\title{
Application of Digital Management Technologies in the Agricultural Insurance Sector
}

\author{
Zaitseva O.P.* \\ Department of Economics, Accounting and Financial \\ Control \\ Omsk State Agrarian University named after P.A. Stolypin \\ Omsk, Russia \\ e-mail: op.zaytseva@omgau.org
}

\author{
Baetova D.R \\ Department of Economics, Accounting and Financial \\ Control \\ Omsk State Agrarian University named after P.A. Stolypin \\ Omsk, Russia \\ e-mail:dr.baetova@omgau.org
}

\author{
Goncharenko L.N \\ Department of Economics, Accounting and Financial Control \\ Omsk State Agrarian University named after P.A. Stolypin \\ Omsk, Russia \\ e-mail: ln.goncharenko@omgau.org
}

\begin{abstract}
The need to use agricultural insurance as a risk management method for agricultural producers is objective. The increasing role of digital technology and the Internet has led to the development of digitalization processes in the agricultural insurance sector. This article discusses features of digitalization of the agricultural insurance sector. The relevance of the study is due to information on the volume of the agricultural insurance market in the Russian Federation and the dynamics of agricultural insurance indicators. The digitalization experience of Russian insurance companies using digital technologies at various stages of interaction with policyholders, including the stages of assessing the object of insurance and losses, is described. The article can be of interest to specialists of state and municipal agricultural management bodies, heads of agricultural organizations and processing enterprises, farmers, agricultural insurance specialists, teachers and students of agricultural universities
\end{abstract}

Keywords - agricultural insurance, digitalization, internetization.

\section{INTRODUCTION}

The agricultural sector in the Russian Federation is very dependent on natural and climatic conditions. Agricultural producers are at risk, planned income is always in doubt, given that at the end of the season the return on costs cannot be guaranteed. The development of rural territories depends on the performance of agricultural organizations. [12]

Thus, the mechanism which can compensate for such risks is required. Such issues are resolved through the insurance system.

The aim of the study is to consider the digitalization of agricultural insurance based on the experience of Russian insurers in promoting digital technologies both at the stage of documentary interaction between the insurer and the insured, and at the stage of evaluating the insurance object and assessing losses. The subject of the study is the impact of digital technology on the insurance market in the context of digitalization of agricultural insurance.

\section{PROBLEM STATEMENT}

During the last four years, there has been a steady increase in damage to farmers from natural emergencies. In 2016, it amounted to 2.1 billion rubles, in $2017-3.6$ billion, in $2018-7.3$ billion, and in $2019-13.2$ billion rubles. In 2019, the government compensated for much more damage - 6.8 billion rubles (in 2018 -3.6 billion). More than 6 billion rubles were allocated to help agricultural producers in the Far East and Irkutsk region. In other regions, according to government regulations, compensation was paid taking into account the availability of insurance coverage. As a result, about 20 regions did not receive emergency compensation: Orenburg region, the Republic of Tatarstan, the Udmurt Republic, and others. However, insurance as a source of compensation for damage, a method of managing risks of agricultural organizations, and anthropogenic risks is an important factor in the sustainable development of natural and anthropogenic complexes in rural areas. [3]

In all countries with the developed agricultural industry, there is an agricultural insurance system. For example, in China about $25-40 \%$ are covered by insurance. In the USA, this share is $90 \%$. [4] In addition, agricultural insurance is one of the elements of infrastructure required for the development of agricultural production. [5]

In Russia, according to the data of 2018, more than 60 thousand agricultral insurance contracts were concluded, of which about 5 thousand contracts were concuded with agricultural organizations. For every 7-8 enterprises, there is one policy. In Russia, there are only about 36 thousand agricultural enterprises. The volume of the agricultural risk insurance market by regions of the Russian Federation is presented in Figure 1.

According to the National Union of Agricultural Insurers, $56 \%$ of 112.1 million rubles in the agricultural insurance market in the Siberian Federal District fall on Omsk Region. [6]

According to the Bank of Russia, the dynamics of insurance premiums and payments, contracts and insurance amounts is ambiguous (Table 1). 


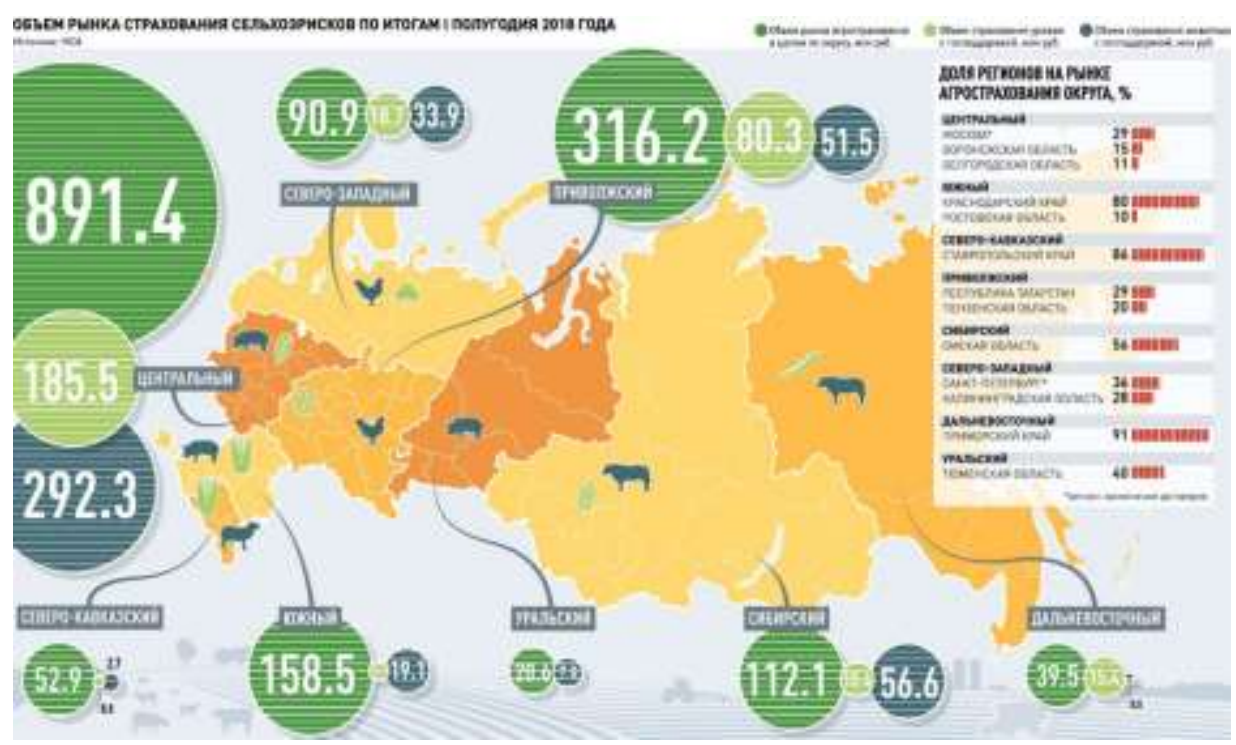

Agricultural insurance market volume in the particular federal district, mln. rub

Total value of harvest insurance services with state subsidies, mln. rub

Total value of cattle insurance services with state subsidies, mln. rub
Agricultural Insurance Market Share $(\%)$

$\begin{array}{lr}\begin{array}{l}\text { Central federal } \\ \text { (ЦЕНТАЛЬНЫЙ) }\end{array} \\ \text { - Moscow } & 29 \\ \text { - Voronezh } & 15 \\ \text { - } \quad \text { Belgorod } & 11 \\ \text { South federal district (ЮЖНЫЙ) } \\ \text { - Krasnodar } \\ \text { - Rostov }\end{array}$

North-Caucasus federal district (СЕВЕРО-КАВКАЗАСКИЙ)

- Stavropol

Volga federal district (ПРИВОЛЖСКИЙ)

- Tatarstan

- Penza

Siberian federal district (СИБИРСКИИ)

- Omsk

North-West federal district (СЕВЕРО-ЗАПАДНЫЙ)

- $\quad$ Saint Petersburg

- Kaliningrad

Far Eastern federal district (ДАЛЬНЕВОСТОЧНЫЙ)

- Vladivostok

Urals federal district

(УРАЛЬСКИЙ)

- Tyumen

Fig. 1. The volume of the agricultural insurance market of the Russian Federation (according to the NSA)

In general, a decrease in agricultural insurance contracts was observed throughout the Russian Federation, but the cost of contracts increased 1.3 times and the amount of insurance premiums -1.5 times, which indicates an increase in the value of the average agricultural insurance contract.

The growth of insurance payments in agricultural insurance is less than the growth of insurance premiums and the value of insurance contracts.

TABLE I. DYNAMICS OF AGRICULTURAL INSURANCE INDICATORS FOR 2018-2019 [7]

\begin{tabular}{|c|c|c|c|}
\hline Parameter & 2018 & 2019 & Dynamics, \% \\
\hline \multicolumn{4}{|c|}{$\begin{array}{c}\text { Information about insurance premiums under insurance contracts, } \\
\text { thousand rubles }\end{array}$} \\
\hline In the RF & 3731184,71 & 5647228,333 & 151 \\
\hline In Omsk region & 101007,07 & 124437,7916 & 123 \\
\hline \multicolumn{4}{|c|}{ Information about payments, thousand rubles } \\
\hline In the RF & 1563519,02 & 2000989,97 & 128 \\
\hline In Omsk region & 295,16 & 2038,69 & 691 \\
\hline \multicolumn{4}{|c|}{ The number of insurance contracts concluded, pcs } \\
\hline In the RF & 65398 & 51882 & 79 \\
\hline In Omsk region & 320 & 356 & 111 \\
\hline \multicolumn{4}{|c|}{$\begin{array}{l}\text { Information on insurance amounts under concluded insurance contracts, } \\
\text { thousand rubles }\end{array}$} \\
\hline In the RF & 340974290,11 & 458862786,06 & 135 \\
\hline In Omsk region & 9783317,74 & 15758085,05 & 161 \\
\hline
\end{tabular}

The situation in agricultural insurance in Omsk Region is somewhat different, but the trend is the same. Against the background of an increase in the number of concluded contracts by $11 \%$, premiums and insurance amounts increase by 23 and $61 \%$, respectively.

Agricultural insurance can be implemented both on the commercial basis and with the use of government support. Despite the fact that commercial insurance can be flexible, the financial burden of a agricultural producer is much lower, insurance should be in compliance with uniform standards, independent expert evaluation, etc. [8]

The trend of popularization of agricultural insurance suggests that by 2022 every third agricultural producer will be a participant in this process.

As for the use of digital technologies in agricultural insurance, it should be noted that the Digital Economy of the Russian Federation program, adopted by order of the Government of the Russian Federation in 2017 contains a list of digital technologies used in the insurance market [9]:

- Big data

- neurotechnology;

- Artificial Intelligence;

- $\quad$ distributed registry systems; 
- quantum technologies;

- production technologies;

- industrial Internet;

- mechanisms of robotics and sensorics;

- wireless technology, virtual and augmented realities.

One of the conditions for the popularization and effectiveness of agricultural insurance is to ensure the availability, manufacturability of insurance services.

Digital innovations can be characterized by the following processes:

1. Innovations in the global market $(2016-\ldots)$ :

- systems for the supply of resources and sales of products;

- $\quad$ automated calculation of agricultural technologies;

- remote monitoring;

- robotization;

2. Development of technologies in the agricultural insurance system of the Russian Federation (NSA):

- $\quad$ implementation of space monitoring on the centralized basis;

- legal status of space monitoring since 2019;

- application of monitoring technologies for the development of index products;

3. Digitalization of the agro-industrial complex as a state program:

- departmental project of the Ministry of Agriculture of the Russian Federation "Digital Agriculture” 2019-2024.

The digitalization of the agricultural sector in Russia is consistent with international practices. Almost all areas of digitalization affect the issues of agricultural insurance

\section{MATERIALS AND METHODS}

Scientific and cognitive methods were used. Inductive and monographic methods made it possible to analyze the digitalization of agricultural insurance elements: interaction of insurers and policyholders, use of digital technologies in the process of evaluating the object of agricultural insurance.

The research information base was compiled by the data of the National Union of Agricultural Insurers and statistical data of the Central Bank of the Russian Federation.

\section{RESULTS}

Digital insurance is an insurance mechanism using digital technology. Moreover, the use of digital technologies by insurance companies can be defined as the digitalization of the insurance market. [8]
The main direction of digitalization of the insurance market is Internetization, i.e. use of the Internet in the business processes of an insurance company.

Based on the trends shown in Table 2, it can be concluded that premiums collected by insurance companies through the Internet have grown more than five times during the reporting period.

TABLE II. DYNAMICS OF PREMIUMS OF INSURERS UNDER CONTRACTS CONCLUDED VIA THE INTERNET IN 2013-2018 [6]

\begin{tabular}{|c|c|c|}
\hline Year & Premiums, million rubles & Increase \% \\
\hline 2013 & 1656 & - \\
\hline 2014 & 1671 & 1 \\
\hline 2015 & 2795 & 67 \\
\hline 2016 & 3158 & 13 \\
\hline 2017 & 5502 & 72 \\
\hline 2018 & 27000 & $\sim 5$ times \\
\hline
\end{tabular}

Internet insurance involves the following areas:

- $\quad$ sales of insurance services;

- $\quad$ settlement of insurance disputes;

- collection of information about policyholders. [10]

The policyholder can choose a specific insurance product; familiarize yourself with the rules of insurance; send documents; calculate costs of insurance services; pay insurance premium; get an insurance policy; amend the insurance contract; apply for an insurance event; get insurance payments.

Some insurers sell policies online. Other insurance companies admit that only some insurance stages can be online (choosing a product, generating a document, calculating a premium), and the remaining stages (payment, getting a policy) can be implemented only in the office. [11]

Factors contributing to the development of the Internet insurance system are as follows:

- $\quad$ increase in the number of Internet users and persons engaged in Internet commerce operations:

- development of legislation governing the interaction of the insurer and the policyholder via the Internet;

- higher profitability of Internet sales of insurance services and settlement of insurance disputes via the Internet;

- a low basic level of online sales in the insurance market in the Russian Federation;

- development of the concept of the Internet of things in the insurance sector;

- more active use of Big Data technologies aimed at personalizing insurance services.

Obstacles to the Internetization of the insurance market are as follows:

- a high level of insurance fraud; 
- potential exposure of online insurance operations to cybercrimes;

- lack of full coverage of the territory of the Russian Federation with high-quality Internet;

- lack of interest of insurers in mass insurance (primarily in auto insurance), which could act as drivers of Internet insurance due to the high level of losses;

- a low level of trust in insurance institutions and insurance culture.

One of the leaders in agricultural insurance is CJSC IC RSHB-Insurance, which occupies half of the agricultural insurance market of the Russian Federation. The process of concluding an agricultural insurance contract is simple and transparent. Figure 2 shows the interaction scheme for CJSC IC RSHB-Insurance and the policyholder.

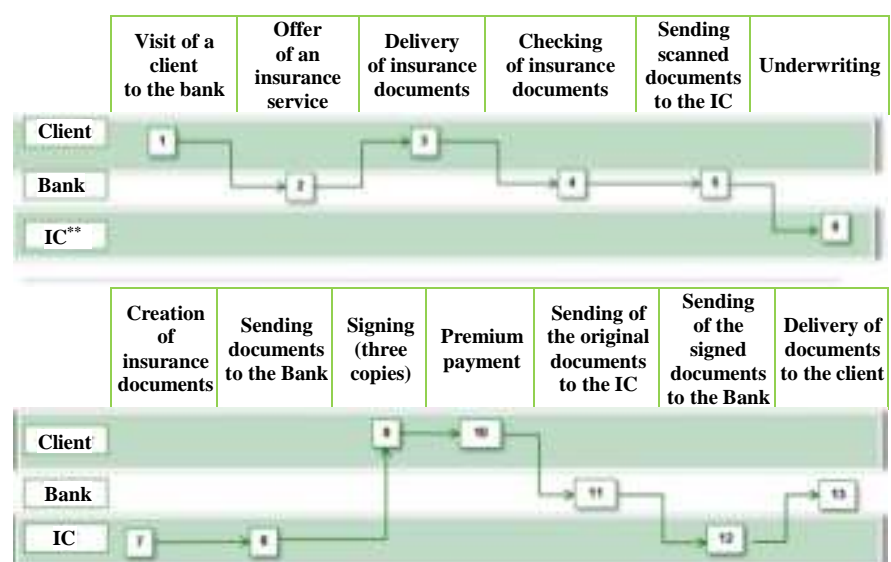

Fig. 2. The scheme of interaction of CJSC IC RSHB-Insurance and the policyholder

In case of occurrence of events provided for by the agricultural insurance contract and if there are disagreements between the parties to the agricultural insurance contract, the Insurer conducts an expert examination at his own expense involving independent experts in order to confirm the occurrence of the insured event and determine the amount of damage (loss) caused to the policyholder. The rules for conducting an examination, requirements for experts, certification conditions and procedure, approved by regulatory legal acts, are applied

The examination is carried out on the basis of a survey of insurance objects and relevant documents, information and materials provided by the insurer and (or) the insured, including those obtained as a result of monitoring using aviation and space equipment.

The digital economy makes it possible to use an individual approach to the policyholder, without increasing the cost of a product or service through the use of modern technologies.

Offers of insurance Internet services depend on the degree of development of Big Data technology, since the main problem in selecting a product is the absence of adequate tools for processing large amounts of data. The presence of a variety of devices for collecting and processing information about the insurance object or the insured expands the list of indicators required for a more accurate and adequate risk assessment. Having received more data, the insurer can create conditions for the insurance program for each specific object or case.

Today, in the global economy, there is a boom in digital technology usedin the agricultural industry. New technologies contribute to the development of sales, new insurance products, more accurate assessment of risks, reduction of loss ratios, etc. In 2018, investment in the development of innovative technologies in the agro-industrial complex amounted to $\$ 1.5$ billion.

State institutions involved in the implementation of the agricultural insurance mechanism (NSA, Ministry of Agriculture, Ministry of Finance and the Bank of Russia) are financing innovative technology development programs.

As part of the AgTech agricultural insurance project, the following areas can be distinguished:

- remote monitoring of the Earth, contributing to the development of index insurance;

- creation of a risk map of the agro-industrial complex and a single information system;

- involvement of agricultural producers in the agricultural insurance system by facilitating their access to insurance information.

Space monitoring data is indispensable in the formation of expert opinions when considering applications from farmers for compensation payments; organizing the agricultural insurance system with state support; assessing circumstances of emergency situations and the state of crops, etc.

The digital registration of agricultural fields is provided for by the departmental project "Digital Agriculture", which the Ministry of Agriculture of Russia adopted at the end of 2018. From 2019 to 2024, the Ministry is going to create a single federal system with information on agricultural lands and the Central Information and Analytical System of Agriculture integrated with the Rosstat and the Federal Customs Service. In these systems, information on land used by farmers and other indicators of farms - crop and livestock production should be combined. Agrarians should have online dashboards through which they will submit applications for subsidies and conclude smart contracts.

The Department of Insurance Expertise and Space Monitoring created by the National Union of Agricultural Insurers is the focal point for the use of agrometeorological data and remote sensing of the Earth.

As part of this direction, the GEOSYS company service (AgriQuest tool) was purchased. It monitors meteorological indicators and the state of crops by the vegetation index throughout the Russian Federation for underwriting, supporting contracts and settling disputes. [6] 
In addition, a new Geosys FieldLogs tool ("Field Inspector") designed to optimize the field survey process using satellite imagery and mobile gadgets in real time is used (Figure 3).
This tool identifies problem areas on the field using highprecision maps and forms an optimal route for the agronomist or expert to inspect the fields.

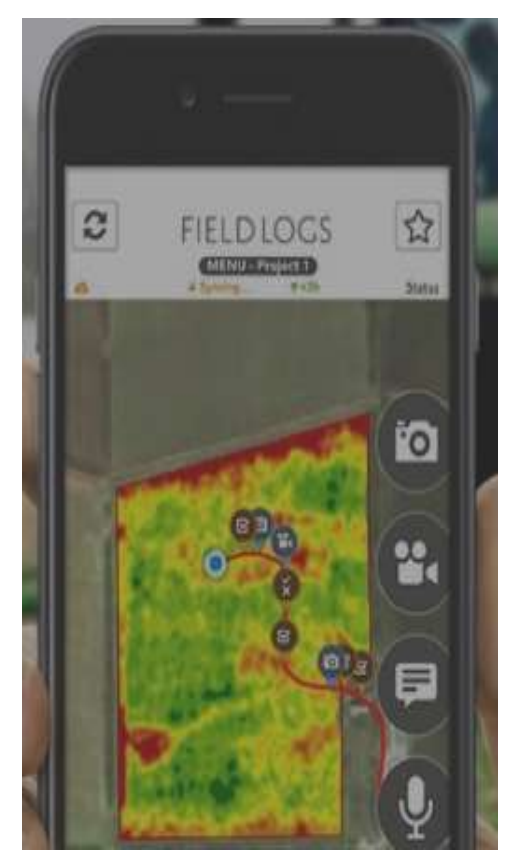

Fig. 3. Digital platform Geosys FieldLogs

The results of using space monitoring instruments for agricultural insurance purposes are graphically presented in Figure 4. The capabilities of space monitoring instruments help insurance organizations to determine the state of crop development by indicators of the vegetation index, which is the main criterion for assessing the state of insured crops. Indicators of the vegetation index can be verified for each region, municipal district, field and for a specific date. In addition, with the help of the tools, one can compare the state of one crop on different fields, as well as determine the heterogeneity in the development of crops on a particular field.
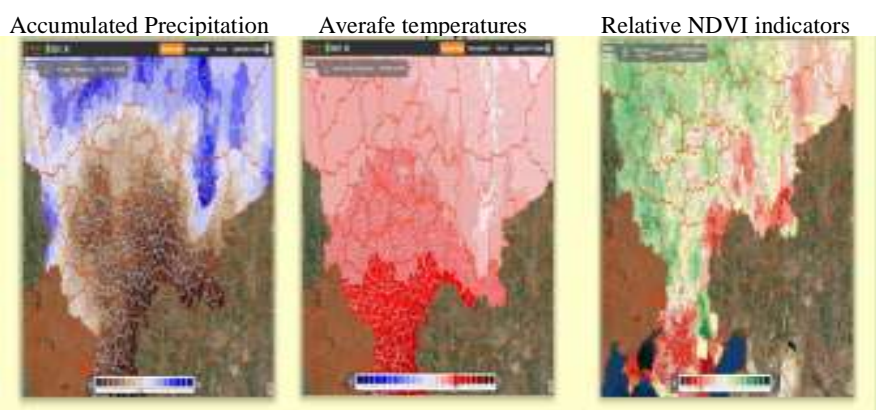

Fig. 4. Space Monitoring Data

Among these tools is a tool developed by Geoscan company which is a Russian group of companies engaged in the development and production of unmanned aerial vehicles
(UAVs), as well as software for photogrammetric data processing and three-dimensional visualization. Geoscan specializes in the production of commercial UAVs of two types: aircraft and multi-rotor ones. One of the main features of drones is that all complexes are created at Geoscana's own production facilities.

GEOSCAN 201 AGRO complex can be used in the agricultural insurance system (Figure 5).

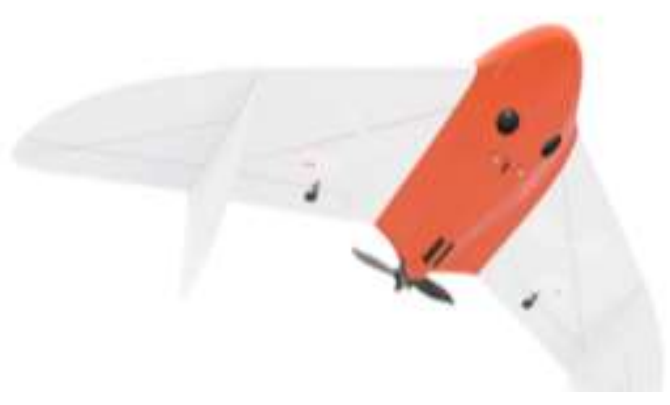

Fig. 5. GEOSCAN 201 AGRO complex

The technologies of this complex make it possible to assess crops using vegetation index maps and specify their conditions according to orthophotomaps and high-resolution images. [12] Geoscan technologies can be applied for the independent assessment of insurance amounts, risk 
management, damage assessment in the event of an insured event. [13]

The economic effect of using this complex for policyholders is due to the improved financial planning. Let us consider the example of a double survey of arable land according to the state of crops and land inventory. On July 2, a survey of 1012 hectares of arable land was conducted. During this survey, 58.6 hectares of problem areas and a discrepancy with the cultivated area of 4.6 hectares were identified. The cost estimate for the problem areas of direct costs amounted to 1.1 million rubles, and for the discrepancy between the planned and actual area amounted to 96,600 rubles. On July 23-24, 4830 hectares of arable land were examined. Vegetation inhibition by 87 hectares was identified (yield loss (corn) - 1914 centners, or 1.7 million rubles). The discrepancy with the actual cultivated area of 14 hectares (estimate of lost revenue per example of soybeans 600 thousand rubles) was also identified.

Thus, the discrepancy between the declared and real areas of arable land of $0.2 \%$ means an increase in direct costs of the agricultural producer by 60 rubles/ha. Inhibition of vegetation by $1.8 \%$ of the area of arable land can lead to lost revenues of about 360 rubles/ha. For comparison, the cost of one examination with a UAV is $20-100$ rubles/ha

The benefits of space monitoring are obvious. Firstly, it is prompt information about the occurrence of events that have signs of an insured event:

- Deviations in crop development by NDVI indices relative to average values;

- Information about the occurrence of an insurance event provided for by the contract, when certain criteria are met.

Secondly, it is the possibility of timely adoption of measures to prevent and reduce losses:

- Prompt notification of the occurrence of the event contributes to the timely adoption of measures aimed at reducing losses;

- Obtaining objective information on the affected areas.

Thirdly, it is the examination cost avoidance:

- Inspections of crops, including those involving independent experts, should be carried out at least 3-5 times during the term of the insurance contract;

- it is not possible to conduct surveys in all areas, but only where deviations in crop development are observed

Fourth, it is the most accurate determination of the yield which eliminates the risk of bad faith of the insured, who can offer the insurer to inspect the most affected areas in order to get the maximum payment. [14]

The economic efficiency of high-tech complexes, which can be used both in the production process and in the agricultural insurance system, leads to an increase in investment in agriculture. [fifteen]
Since 2019, due to changes in the legislation on agricultural insurance, remote monitoring methods have been used for insurance examinations on a legal basis. This creates the basis for creating innovative insurance products, primarily index insurance of crops, which can increase the availability of crop insurance for small and medium-sized farmers.

\section{CONCLUSION}

The use of high-tech complexes in agricultural insurance stimulates the development of agricultural technologies. Partially, the requirements for agricultural technologies are incuded in the current rules for agricultural crop insurance, planting of perennial plantations. Today, the use of agricultural technologies is beneficial for agricultural producers. They ensure stable crops and favorable insurance conditions, in particular, reduction in insurance tariffs, full insurance payment. In addition, modern agricultural technologies help reduce risks, and make insurance more affordable for farmers.

\section{References}

[1] D.S. Nardin, S.A. Nardina, A.V. Zinich, O.A. Blinov, "Impact of organizational and economic models of agricultural organizations on the living standards of the rural population", Int. J. of Mechan. Engineer. and Technol., vol. 9, iss. 11, pp. 2048-2056, 2018.

[2] O.V. Kosenchuk, V.V. Aleshchenko, V.F. Stukach, A.V. Zinich, V.V. Leushkina, "Study of the problems of sustainable development of rural territories", Int. J. of Econ. Res., vol. 13, iss. 6, pp. 2391-2407, 2016

[3] D.S. Nardin, S.A. Nardina, "Sustainable development management of natural-anthropogenic complexes of rural territories", J. of Advan. Res. in Dynamical and Control Syst., vol. 12, iss. 3, pp. 1447-1452, 2020.

[4] A.A. Tsyganov, D.V. Bryzgalov, "Digitalization of the insurance market: tasks, problems and prospects Economy", Taxes. Law, no 2 , pp. 111-120, 2018.

[5] V.F. Stukach, G.K. Saparova, G.T. Sultanova, S.A. Saginova, "Infrastructural development of agricultural products in the republic of Kazakhstan”, Econ. of Reg., vol. 15, iss. 2, pp. 561-575, 2019.

[6] NSA: the development of digital technologies in agricultural insurance should be included in the context of state policy on agriculture. Retrieved from: http://www.dairynews.ru/news/nsa-razvitie-tsifrovykhtekhnologiy-v-agrostrakhov.html

[7] Statistical indicators and information on individual insurance entities Retrieved from: https://cbr.ru/insurance/reporting_stat/

[8] O.V. Shumakova, O.N. Kryukova, T.G. Mozherina, "Ensuring sustainable development of the agricultural economy on the basis of a project-oriented approach to the formation of an effective agri-food market”, Basic res., no. 12-2, pp. 293-298, 2018.

[9] G.I. Shepelin, "Modern cyber risks and insurance: state and prospects", Insurance, no. 9, pp. 21-29, 2017.

[10] A.B. Yakushin, "Insurance telematics and its role in the development of the voluntary insurance market of the Russian Federation", Insurance, no. 5, pp. 25-29, 2016.

[11] D.V. Bryzgalov, "Internet insurance: own and partner sales, indicators, development prospects", Corporate Econ, vol. 2, no. 6, pp. 39-46, 2016.

[12] G. Bikbulatova, E. Kupreyeva, L. Pronina, M. Shayakhmetov, "Using Remote Sensing Methods in Precision Agriculture", 2019 [Proc. of the Int. Sci. Conf. The Fifth Technol. Order: Prospects for the Development and Modernizat. of the Russ. Agro-Industr. Sector].

[13] UAV for agriculture. Retrieved from: https://www.geoscan.aero/ru/ application/agriculture

[14] N. Parkhomenko, A. Garagul, M. Shayakhmetov, "The Use of Remote Sensing Methods to Study the Ecological State of Agricultural Soils", 
2019 [Proceedings of the International Scientific Conference The Fifth Technological Order: Prospects for the Development and Modernization of the Russian Agro-Industrial Sector]
[15] I. Volkov, S. Suslov, N. Zavivayev, R. Bazhenov, Dolmatova, "Current Approaches to Intensified Investments Needed in Agribusiness", 2019 [Int. Sci. and Technol. Conf. on FarEastCon-2019, ed. D.B. Solovev]. Institute of Physics Publishing, no. 072020 